\title{
Investigation of Adhesion Behaviour of Different Underlayered DLC Coated Cold Forming Tool Steel
}

\author{
Noemi Laszlo \\ Department of Industrial Materials Technology, Engineering Division, Bay Zoltán Nonprofit \\ Ltd. for Applied Research, 3519 Miskolc, Hungary (noemi.laszlo@bayzoltan.hu)
}

\begin{abstract}
Mono- and multilayer coatings can be suitable alternatives to traditional bulk materials due to their favorable mechanical properties. Thanks to the ever-evolving coating technology and process, there are a wide variety of coating types today, such as soft, hard, or super-hard coatings that can be made with single or multilayer coatings.

Adhesion and damage to coatings is especially important for coated tools, where damage to the coating can reduce tool life and result in deterioration of the surface quality of the product. The coatings were characterized by Calotest layer thickness measurement, AFM assisted roughness measurement and microhardness test. The adhesion test of the different underlayered (TiBN, CrN and TiAIN) DLC coated Böhler K100 forming tool steel is designed with the Mercedes test (Rockwell C Adhesion Test), which is frequently used to classify the layers, and is complemented by instrumented scratch test.
\end{abstract}

Author Keywords. Coating, DLC, Tool Steel, Coldforming, Ceramic.

Type: Research Article

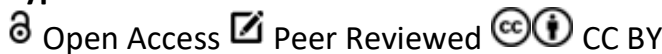

\section{Introduction}

The most effective way to increase the tribological performance of sheet metal forming tools is possible with self-lubricating, mono- and multi-layer ceramic coatings (Ghiotti and Bruschi 2011; Podgornik, Hogmark, and Sandberg 2006). Initially, the coatings were applied to the substrate in only one layer -called monolayer coatings - but this did not always form a permanent bond between the coating and the substrate (Carlsson and Olsson 2006). Later, multi-layer coatings appeared, in which not only a single material is applied in the form of an underlayer, but several different layers are formed under the coating.

In recent years, a new generation of coatings has come to the fore. These Diamond-LikeCarbon (DLC) coatings (Tyagi et al. 2019), in addition to their high hardness (1500-3200 HV), are due to their extremely low friction (Nuruzzaman et al. 2011) compared to conventional PVD coatings (Hieke et al. 2005) (e.g. nitride coatings), which can be up to 5-10 times lower (Huang, Guo, and Kao 2010). The unique combination of these properties has opened up new possibilities in the protection against various wear damages, allowing the wear of mechanical parts exposed to wear, such as engine parts, etc. development. These coatings, among other advantages, are generally biocompatible (Allen, Myer, and Rushton 2001; Dearnaley and Arps 2005), therefore, they are also suitable for food processing and medical applications (Ma, Ruys, and Zreiqat 2009), as are PACVD (Mitterer et al. 2003) coatings.

These composite coatings generally comprise carrier layers of different materials, such as $\mathrm{Cr}$, $\mathrm{CrN}, \mathrm{Si}, \mathrm{W}$ and WC-C, followed by an amorphous carbon-enriched upper functional layer. 
The selection of the substrate is based on several criteria. These include requirements for adhesion, mode of damage, type and geometry of contact surfaces, applied load and other metallurgical considerations (Pellier et al. 2017).

The DLC coating is a metastable form of amorphous carbon (McColl, Wood, and Grant 1994) formed largely of sp3-hybrid carbon atoms (Celii and Butler 1991).

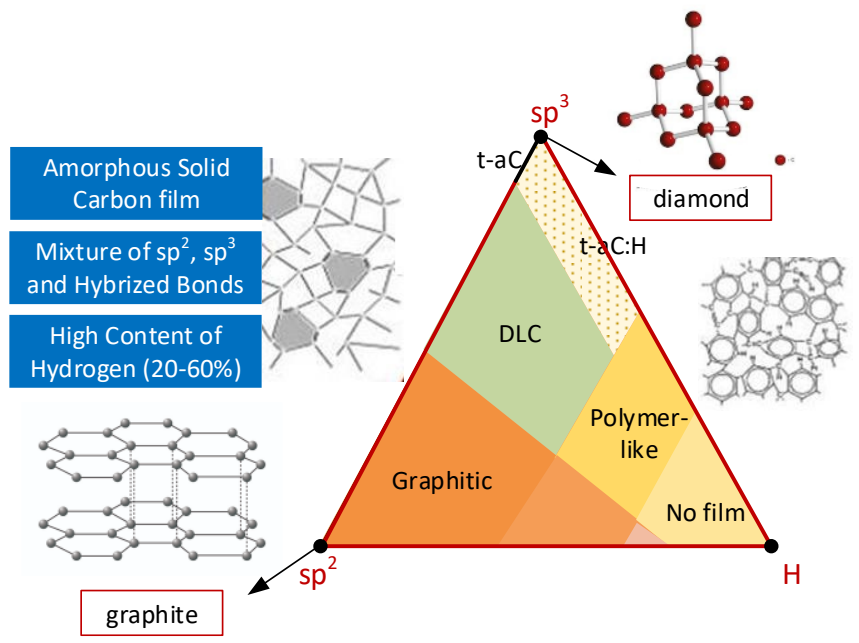

Figure 1: DLC coating interpretation scheme (Casiraghi, Robertson, and Ferrari 2007): amorphous carbon: a-C; amorphous carbon with tetrahedral structure: ta-C; amorphous carbon + hydrogen: $\mathrm{a}-\mathrm{C}: \mathrm{H}$; tetrahedral amorphous carbon + hydrogen:

ta-C:H

The structure of DLC coating films (Kiryukhantsev-Korneev and Bondarev 2019), moving from the substrate to the top of the coating, can be divided into three zones (Erdemir 2000; Zhang et al. 2015):

- the components of the surface substrates are mixed with carbon;

- the real DLC layer with sp3 bonds;

- the more graphitic thin surface layer (Bewilogua and Hofmann 2014).

Characterization of the tribological performance (Renman 2012; Sedlaček, Podgornik, and Vižintin 2008) of different coatings is possible with several test methods (Horiuchi et al. 2009; Michalczewski et al. 2002). The scratch resistance (Zaidi et al. 2006) and the adhesion properties (Waseem et al. 2014) of the coatings are investigated in this article.

\section{Examination and Results}

\subsection{Materials}

The base material of the test specimens examined during the measurements is K100 cold forming tool steel. The EN number of the tool steel is 1.2080, the EN symbol for its composition is $\mathrm{X} 210 \mathrm{Cr} 12$. Its chemical composition is shown in Table 1.

\begin{tabular}{cccccccccc}
\hline $\mathbf{C}$ & $\mathbf{S i}$ & $\mathrm{Mn}$ & $\mathrm{Cr}$ & $\mathbf{M o}$ & $\mathbf{N i}$ & $\mathbf{V}$ & $\mathbf{W}$ & Co & Other \\
1,55 & 0,30 & 0,30 & 11,30 & - & - & - & - & - & - \\
\hline
\end{tabular}

Table 1: Chemical composition of $X 210 \mathrm{Cr} 12$ coldforming tool steel

The fabric structure of the material is ledeburite, there is a slight change in size during heat treatment. The specimens were made of $20.8 \mathrm{~mm}$ diameter rods, $20 \mathrm{~mm}$ high cylinders by machine cutting in the softened state. The rollers were then ground on the two end faces, followed by heat treatment and polishing. The heat treatment of the K100 cold forming tool steel consists of hardening and tempering. Training is performed in a vacuum oven at $980^{\circ} \mathrm{C}$. Holding was necessary for 15-30 minutes after the full heat treatment. Cooling is possible with 
oil, salt bath or gas. In the case of the test specimens, the pieces were cooled in nitrogen under an overpressure pressure of 6 Bar. After hardening, the tempering took place at $350^{\circ} \mathrm{C}$. The hardness after heat treatment on the test pieces was 57-61 HRC.

\subsection{Thickness and microhardness of coatings}

The layer thickness of the coatings was determined using a Calotest equipment. The test was performed with a $30 \mathrm{~mm}$ diameter steel ball. Due to differences in the mechanical properties of the coatings, the samples were abraded for different periods of time. TiBN-coated specimens were abraded for $3 \mathrm{~min}$, while for different underlay DLC-coated specimens, a test time of 5 min was used because the upper DLC layer had already ruptured during this abrasion time. The results of the study are summarized in the Table 2.

\begin{tabular}{lcccc}
\hline & TiBN & $\begin{array}{c}\text { TiBN }+ \\
\text { DLC }\end{array}$ & $\begin{array}{c}\text { TiAIN+ } \\
\text { DLC }\end{array}$ & $\begin{array}{c}\text { CrN }+ \\
\text { DLC }\end{array}$ \\
\hline Thickness of TiBN / TiAIN / CrN layer $[\mu \mathrm{m}]$ & 2,207 & 2,04 & 1,72 & 1,341 \\
Thickness of the WC layer $[\mu \mathrm{m}]$ & - & 0,72 & 0,562 & 0,474 \\
Thickness of DLC layer $[\mu \mathrm{m}]$ & - & 1,461 & 1,472 & 1,5 \\
$\Sigma$ Thickness $[\mu \mathrm{m}]$ & 2,207 & 4,22 & 3,75 & 3,315 \\
HV0.1 & 401,4 & 474,4 & 475,2 & 552 \\
\hline
\end{tabular}

Table 2: Thickness and microhardness of multilayered DLC coatings

\subsection{Surface roughness}

An AFM microscope was used to determine the surface roughness of the coatings. A tapping test method was used during the examinations, the size of the area scanned during the examination was 4900 ?m. An actual profile was selected during scanning with the touch probe in the test area. During the tests, the $2 \mathrm{D}$ roughness parameters of the coated specimens were determined. The results of AFM measurements are shown in Figure 2 and Table 3.
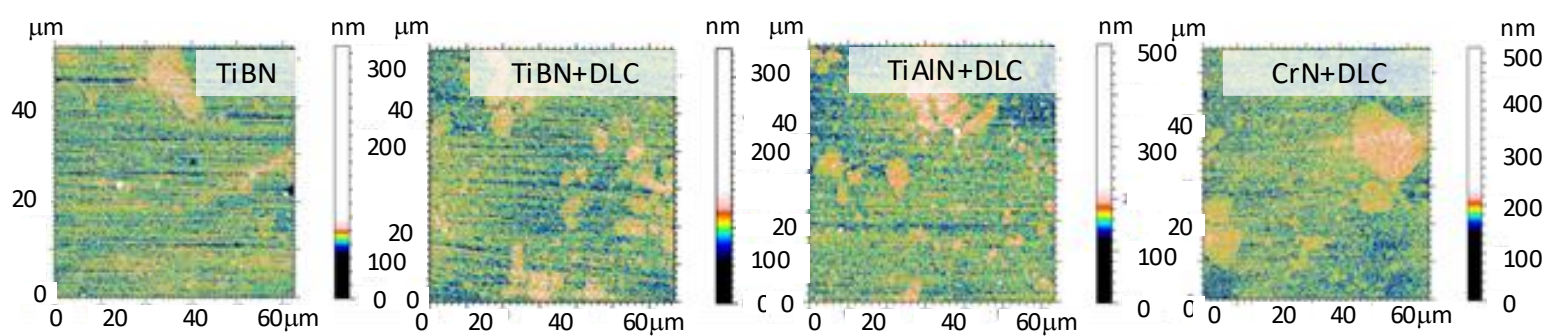

Figure 2: AFM surface topography for DLC coated tool steels: TiBN; TiBN+DLC;TIAIN+DLC; CrN+DLC

\begin{tabular}{ccccc}
\hline SR, $\mathbf{m m}$ & TiBN & TiBN+DLC & TiAIN+DLC & CrN+DLC \\
\hline Ra & 156 & 93,4 & 110 & 107 \\
$\mathrm{Rz}$ & 19,3 & 13,9 & 14,2 & 14,3
\end{tabular}

Table 3: Ra and Rz roughness parameters for different underlayered DLC coatings

Based on the results, it can be concluded that the use of DLC coatings can significantly reduce the surface roughness. This is especially noticeable for TiBN and TiBN + DLC coatings. However, there is no significant difference in surface roughness for $\mathrm{R}_{z}$ parameters. However, there is a difference in the surface roughness $R_{a}$, in which case the TiBN + DLC coating has the lowest roughness and the TiAIN + DLC the largest. Based on these, it can be stated that the effect of the underlayer on the roughness parameter $R_{z}$ is practically negligible, the roughness parameter $R_{a}$ can be better applied to characterize these coatings. 


\subsection{Rockwell C adhesion test}

In our research, the adhesion of TiBN, TiBN + DLC, TiAIN + DLC and CrN + DLC coatings was investigated using Rockwell-C adhesion test (Broitman and Hultman 2012). VDI 3198 specifies the Rockwell-C hardness test method (Vidakis, Antoniadis, and Bilalis 2003) for testing coated surfaces (Kayali and Taktak 2015). During the test, a diamond cone was pressed into the specimen with a loading force of $1500 \mathrm{~N}$. The resulting impression was imaged using a light microscope (Heinke et al. 1995). The figures were compared (Haršáni et al. 2018) with the standard illustrations in the standard. The scale (Flores-Rentería et al. 2015) used for visual inspection is illustrated in Figure 3.

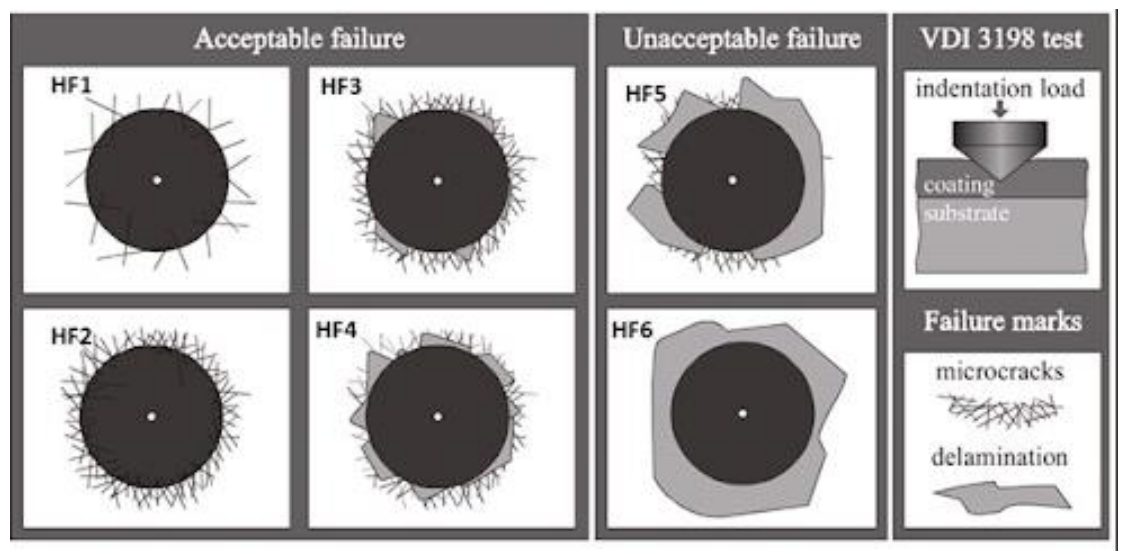

Figure 3: The VDI3198 scale used during the Mercedes test

Microscopic images of imprints of specimens with different coatings are given in Figure 4. The figure shows, that TiBN, TiAIN + DLC, TiBN + DLC and CrN + DLC coatings are among the acceptable coatings according to the classification in VDI 3198. Despite the defective piercing tool, it can be stated that in the case of TiBN coating no microcracks are visible on the microscopic image, while in the case of TiAIN + DLC coating there is a radial microcrack at the edge of the imprint, but their number is small.
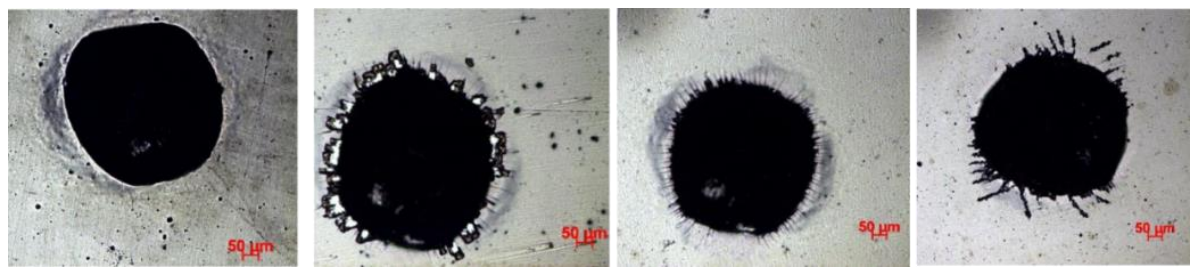

Figure 4: Microscopic images taken during Rockwell-C adhesion testing of various underlayered DLC coatings (parameters: Standard: VDI3198; Loading force: 1500 N; Tool: $120^{\circ}$ diamond spheroconical

CrN + DLC coatings have smaller cracks than TiAIN + DLC coatings, but are denser along the imprint, however, in the case of $\mathrm{CrN}$-based coatings the layered coating caused by the plastic deformation of the substrate can be observed, but its extent still meets the standard. In the case of the TiBN + DLC coating, the TiBN layer adheres strongly to the base material, however, larger microcracks can already be observed at the edge of the imprint, followed by layered deposition of the coating. This means that the adhesion of the coating to the base material is adequate, however, the coating is brittle due to the brittleness of the DLC coating. However, such damage is considered acceptable as required by the standard.

\subsection{Instrumented scratch test}

An SP-15 instrumented scratch tester was used to determine the peeling and adhesion properties of the coatings. The custom-developed equipment combines an optical microscope and a special hardness tester. The loading mode was linearly increasing, normal load, the 
applied force was 2-150 N, the scratch length is $15 \mathrm{~mm}$, and the feed velocity of table is $5 \mathrm{~mm} / \mathrm{min}$.With the set test parameters, one sample for each coating type three scratch tests were performed, the results obtained were the tangential force - friction coefficient diagrams were recorded. Each coating type has friction coefficient and scratch path length relationship for 1-1 scratch test in case of registries. The critical loading force and the coefficient of friction in case of different coatings is shown in Table 4.

\begin{tabular}{ccc}
\hline Coating type & Coefficient of friction, 国]国] & $\begin{array}{c}\text { Critical force, } \\
\text { Fcrit, [N] }\end{array}$ \\
\hline TiBN & 0.18 & 105 \\
TiBN+DLC & 0.17 & 100 \\
TiAIN+DLC & 0.11 & 42 \\
CrN+DLC & 0.15 & 80 \\
\hline
\end{tabular}

Table 4: The friction coefficient and critical force in case of DLC coatings

(parameters: linearly increasing, normal loading force: $2-150 \mathrm{~N}$, feed velocity of table: $5 \mathrm{~mm} / \mathrm{min}$, scratch length: $10 \mathrm{~mm}$

Critical loading force $\left(F_{c}\right)$ required to release the coating in the case of a TiBN coating is $105 \mathrm{~N}$ and the coefficient of friction is 0.18 . Using a DLC layer is critical load value is 0.17 , critical load value is $100 \mathrm{~N}$. During the tests it was observed that the coating tears relatively late $(10 \mathrm{~mm}$ scratch distance), the DLC coated sample had a quieter bouncing sound, which may indicate cracking of the DLC layer (Figure 5).

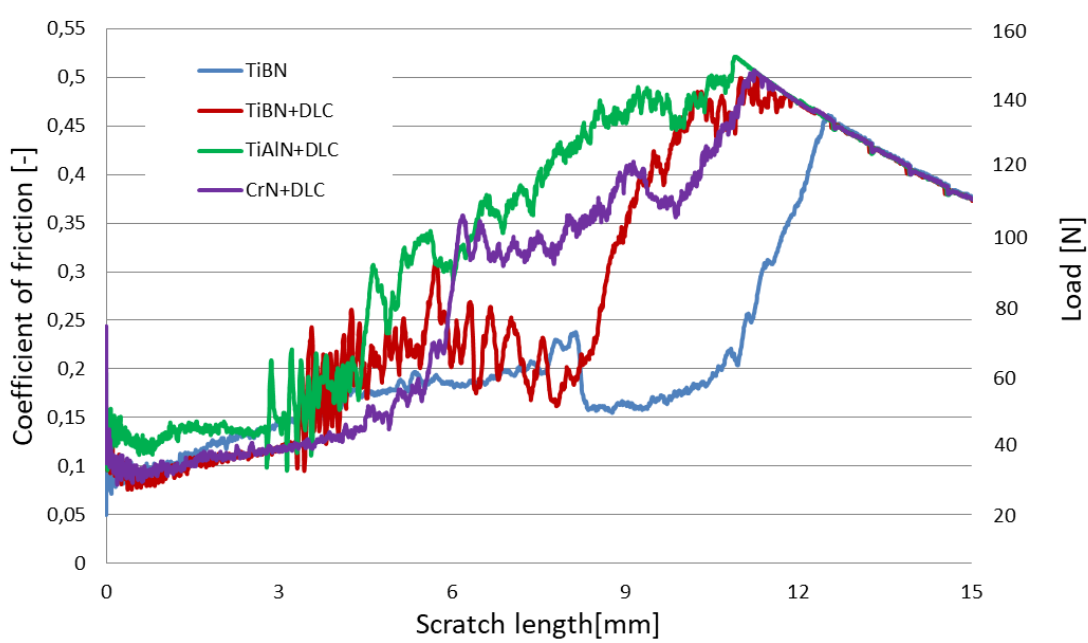

Figure 5: Coefficient of friction - scratch length diagram in case of TiBN; TiBN+DLC; TiAIN+DLC and CrN+DLC multilayered coatings

During the scratch inspection of the TiAIN + DLC coating, the coating detached from the TiBN much earlier compared to underlay coatings. In this case, the coating is required for peeling critical load is $42 \mathrm{~N}$, the value of the coefficient of friction compared to TiBN systems lower, around 0.1-0.12.

For CrN + DLC coatings, the coefficient of friction is around 0.15 - similarly for TiBN coating systems - critical load is $80 \mathrm{~N}$. However, it can be seen from the diagram that it takes more time than the coating to tear off In the case of a TiAIN underlayer, however, it detaches earlier than the TiBN coating system. It can be determined on the basis of the scratch tests performed. that the various one and the scratch resistance of multilayer coatings is typically different, the layer detachment characteristic critical loading force of the TiBN coated sample is the largest, the DLC in the case of coatings with a top coat, presumably due to early damage to the top coat, a critical load is less. 
To investigate the effect of hardness on adhesion properties, the hardnesses of the coatings were plotted as a function of critical loading forces. Based on these, we obtained the following diagram (Figure 6).

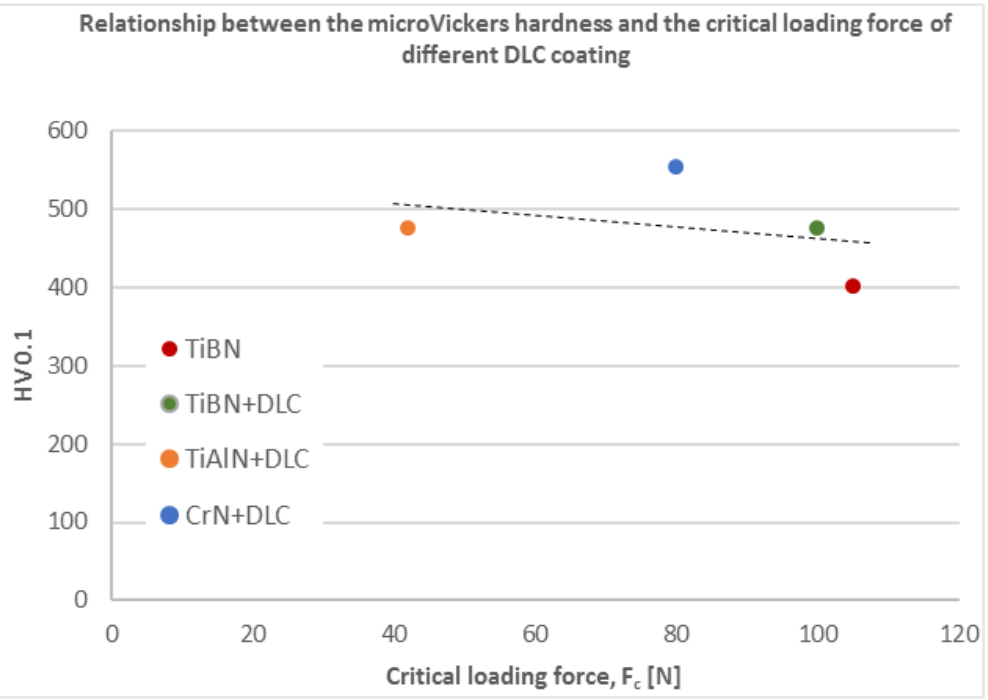

Figure 6: The relationship between the critical loading force and microhardness of TiBN and mulitlayered DLC coatings

Based on Figure 6, Equation (1) can be written between hardness and critical loading force: $y=(-0.759 x)+537,8$

From the above equation and the diagram, it can be concluded that there is a clear relationship between the hardness of the coating and the critical load force, the load force required to detach the coating increases as the hardness of the coating decreases. The main reason for this is that the higher hardness coating is more brittle and therefore bounces off the surface much more easily, while the softer coating is more resistant to plastic deformation caused by scratch needles. This finding can be related to the results of the Mercedes tests of DLC coatings, as there is practically no damage along the imprint of the lowest hardness TiBN coating. At the same time, the higher hardness coatings were less resistant during the test and cracks and detachments were observed along the imprints. However, it is important to note that although the DLC layer may be damaged, the more flexible underlayer underneath can still protect the base material from damage.

\section{Conclusion}

In our research, the adhesion properties of various underlay DLC coatings were investigated using Rockwell adhesion testing and instrumented scratch testing. The results of the studies can be summarized as follows:

1. The Rockwell-C adhesion test is suitable for the qualitative description of the adhesion properties of coatings, but does not provide quantitative results. Based on the tests performed, the coatings can be considered suitable for adhesion.

2. It can be determined based on the scratch tests performed, that the scratch resistance of different single and multilayer coatings is typically different, the critical loading force characteristic of layer deposition in the TiBN coated sample is the largest, the critical loading force is lower for coatings with a DLC topcoat, presumably due to early layer damage.

3. The Rockwell $\mathrm{C}$ adhesion test, supplemented by an instrumented scratch test, may be suitable for DLC coated tool steels for a broader description of the adhesion properties of coatings. 
4. Studies have shown that the hardness of coatings can affect the scratch resistance of the base material: softer coatings perform better in this respect than coatings with higher hardness.

\section{References}

Allen, M., B. Myer, and N. Rushton. 2001. "In vitro and in vivo investigations into the biocompatibility of diamond-like carbon (DLC) coatings for orthopedic applications". Journal of Biomedical Materials Research 58, no. 3: 319-28. https://doi.org/10.1002/10974636(2001)58:3<319::Aid-Jbm1024>3.0.Co;2-F.

Bewilogua, K., and D. Hofmann. 2014. "History of diamond-like carbon films - From first experiments to worldwide applications". Surface \& Coatings Technology 242: 214-25. https://doi.org/10.1016/j.surfcoat.2014.01.031.

Broitman, E., and L. Hultman. 2012. "Adhesion improvement of carbon-based coatings through a high ionization deposition technique". Journal of Physics: Conference Series 370: 012009. https://doi.org/10.1088/1742-6596/370/1/012009.

Carlsson, P., and M. Olsson. 2006. "PVD coatings for sheet metal forming processes - A tribological evaluation". Surface and Coatings Technology 200, no. 14: 4654-63. https://doi.org/10.1016/j.surfcoat.2004.10.127.

Casiraghi, C., J. Robertson, and A. C. Ferrari. 2007. "Diamond-like carbon for data and beer storage". Materials Today 10, no. 1-2: 44-53. https://doi.org/10.1016/S13697021(06)71791-6.

Celii, F. G., and J. E. Butler. 1991. "Diamond chemical vapor-deposition". Annual Review of Physical Chemistry 42: 643-84. https://doi.org/10.1146/annurev.pc.42.100191.003235.

Dearnaley, G., and J. H. Arps. 2005. "Biomedical applications of diamond-like carbon (DLC) coatings: A review". Surface \& Coatings Technology 200, no. 7: 2518-24. https://doi.org/10.1016/j.surfcoat.2005.07.077.

Erdemir, A. 2000. "Solid lubricants and self-lubricating films". In Modern tribology handbook, 787-825. CRC Press. https://doi.org/10.1201/9780849377877.

Flores-Rentería, M. A., M. Ortiz-Dominguez, M. Keddam, O. Damían-Mejia, M. Elias-Espinosa, M. A. Flores-González, S. A. Medina-Moreno, A. Cruz-Avilés, and M. Villanueva-Ibañez. 2015. "A simple kinetic model for the growth of Fe2B layers on AISI 1026 steel during the powder-pack boriding". High Temperature Materials and Processes 34, no. 1: 1-11. https://doi.org/10.1515/htmp-2014-0004.

Ghiotti, A., and S. Bruschi. 2011. "Tribological behaviour of DLC coatings for sheet metal forming tools". Wear 271, no. 9-10: 2454-58. https://doi.org/10.1016/j.wear.2010.12.043.

Haršáni, M., N. Ghafoor, K. Calamba, P. Zacková, M. Sahul, T. Vopát, L. Satrapinskyy, M. Čaplovičová, and L. Čaplovič. 2018. "Adhesive-deformation relationships and mechanical properties of nc-AlCrN/a-SiNx hard coatings deposited at different bias voltages". Thin Solid Films 650: 11-19. https://doi.org/10.1016/j.tsf.2018.02.006.

Heinke, W., A. Leyland, A. Matthews, G. Berg, C. Friedrich, and E. Broszeit. 1995. "Evaluation of PVD nitride coatings, using impact, scratch and Rockwell-C adhesion tests". Thin Solid Films 270, no. 1-2: 431-38. https://doi.org/10.1016/0040-6090(95)06934-8.

Hieke, A., T. Hurkmans, G. J. van der Kolk, M. Tobler, and R. Bonetti. 2005. "Comparison between WCC/DLC, CrN/DLC and RF produced DLC coatings". Proceedings of the annual technical conference 48: 556-61. 
Horiuchi, T., K. Yoshida, M. Kano, M. Kumagai, and T. Suzuki. 2009. "Evaluation of adhesion and wear resistance of DLC films deposited by various methods". Plasma Processes and Polymers 6, no. 6-7: 410-16. https://doi.org/10.1002/ppap.200930004.

Huang, T. H., J. U. Guo, and C. T. Kao. 2010. "A comparison of the friction associated with diamond-like carbon (DLC) or titanium nitride (TiN) plating metal brackets". Surface \& Coatings Technology 205, no. 7: 1917-21. https://doi.org/10.1016/j.surfcoat.2010.08.070.

Kayali, Y., and S. Taktak. 2015. "Characterization and Rockwell-C adhesion properties of chromium-based borided steels". Journal of Adhesion Science and Technology 29, no. 19: 2065-75. https://doi.org/10.1080/01694243.2015.1052617.

Kiryukhantsev-Korneev, F. V., and A. V. Bondarev. 2019. "Structure and properties of antifriction $\mathrm{Cu}, \mathrm{Cu}-\mathrm{C}$, and DLC coatings". Physics of Metals and Metallography 120, no. 7: 702-08. https://doi.org/10.1134/S0031918×19050089.

Ma, W., A. J. Ruys, and H. Zreiqat. 2009. "Diamond-like carbon (DLC) as a biocompatible coating in orthopaedic and cardiac medicine". In Cellular response to biomaterials, 391426. Woodhead Publishing. https://doi.org/10.1533/9781845695477.2.391.

McColl, I. R., J. V. Wood, and D. M. Grant. 1994. "Diamond and diamond like carbon coatings". Transactions of the IMF 72, no. 3: 120-23. https://doi.org/10.1080/00202967.1994.11871035.

Michalczewski, R., W. Piekoszewski, M. Szczerek, and W. Tuszynski. 2002. "A method for the tribological testing of thin, hard coatings". Tribotest 9, no. 2: 117-30. https://doi.org/10.1002/tt.3020090204.

Mitterer, C., F. Holler, D. Reitberger, E. Badisch, M. Stoiber, C. Lugmair, R. Nobauer, T. Muller, and R. Kullmer. 2003. "Industrial applications of PACVD hard coatings". Surface \& Coatings Technology 163: 716-22. https://doi.org/10.1016/S0257-8972(02)00685-0.

Nuruzzaman, D. M., M. A. Chowdhury, A. Nakajima, M. L. Rahaman, and S. M. I. Karim. 2011. "Friction and wear of diamond like carbon (DLC) coatings - A review". Recent Patents on Mechanical Engineering 4, no. 1: 55-78. https://doi.org/10.2174/2212797611104010055.

Pellier, J., J. Y. Paris, J. Denape, J. Bry, and V. Genissieux. 2017. "General procedure for selecting and testing materials and coatings in response to a tribological problem". Journal of Tribology-Transactions of the Asme 139, no. 3. https://doi.org/10.1115/1.4034331.

Podgornik, B., S. Hogmark, and O. Sandberg. 2006. "Proper coating selection for improved galling performance of forming tool steel". Wear 261, no. 1: 15-21. https://doi.org/10.1016/j.wear.2005.09.005.

Renman, V. 2012. "Tribological testing of DLC coatings for automotive applications". Independent thesis, advanced level, Department of Engineering Sciences, Uppsala University. http://urn.kb.se/resolve?urn=urn:nbn:se:uu:diva-177355.

Sedlaček, M., B. Podornik, and J. Vižintin. 2008. "Tribological properties of DLC coatings and comparison with test results: Development of a database". Materials Characterization 59, no. 2: 151-61. https://doi.org/10.1016/j.matchar.2006.12.008.

Tyagi, A., R. S. Walia, Q. Murtaza, S. M. Pandey, P. K. Tyagi, and B. Bajaj. 2019. "A critical review of diamond like carbon coating for wear resistance applications". International Journal of $\begin{array}{llllll}\text { Refractory Metals } \quad \text { \& Hard } & \text { 107-22. }\end{array}$ https://doi.org/10.1016/j.ijrmhm.2018.09.006. 
Vidakis, N., A. Antoniadis, and N. Bilalis. 2003. "The VDI 3198 indentation test evaluation of a reliable qualitative control for layered compounds". Journal of Materials Processing Technology 143: 481-85. https://doi.org/10.1016/S0924-0136(03)00300-5.

Waseem, B., S. Alam, M. Irfan, M. Shahid, B. D. Soomro, S. Hashim, and R. Iqbal. 2014. "Optimization and characterization of adhesion properties of DLC coatings on different substrates". IOP Conference Series: Materials Science and Engineering 60. https://doi.org/10.1088/1757-899x/60/1/012054.

Zaidi, H., A. Djamai, K. J. Chin, and T. Mathia. 2006. "Characterisation of DLC coating adherence by scratch testing". Tribology International 39, no. 2: 124-28. https://doi.org/10.1016/j.triboint.2005.04.016.

Zhang, L., X. Wei, Y. Lin, and F. Wang. 2015. "A ternary phase diagram for amorphous carbon". Carbon 94: 202-13. https://doi.org/10.1016/j.carbon.2015.06.055. 